\title{
TEACHER'S WRITTEN CORRECTIVE FEEDBACK ON STUDENTS' TRANSLATION IMPROVEMENT
}

\author{
Kalsum, Magdahalena \\ Institut Agama Islam Negeri (IAIN) Parepare \\ Magdahalena_tj@yahoo.com, kalsumkhalil@gmail.com
}

\begin{abstract}
This research aims to investigate the teacher's written corrective feedback toward the students' translation improvement. It is focused on the students' translation on lexical and grammatical mistakes in translating the source text into the target text. Translation is an activity that aims to facilitate the communication process by interpreting the information received in one language into another language. However, the mistakes while translating cannot be avoid by the translator or the students. The students are commonly done mistakes lexically and grammatically. To overcome the mistakes, the teacher will be a facilitator in correcting the students' translation. Implementing of written corrective feedback is provided teacher to correcting the students' mistakes by writing their comments, correction of errors, etc. on the students' writing translation. Based on the analysis, the result indicates that the students make mistakes in translating, the students are most commonly made some mistakes in lexical and grammatical errors.
\end{abstract}

Keywords: Translation, Teacher' Written Corrective Feedback

\section{INTRODUCTION}

In daily cross linguistics communication, people always do translation in formal and informal form. Of course, a formal communication requires a more effective translation process and expertise that guarantee the equivalence and correctness of the meaning of the messages between the original language and the target language. In curriculum of Indonesia, translation is not introduced as the specific focus in learning English at the Junior High School. The school students understood the learning based on their own knowledge in translating the textbook.
The variety of beginners' translation courses to advanced courses are designed to train students to be able to do effective translations. Although some of the students have completed some translation courses, their performance is still far from the basic requirement of translation, for example, correctness and equivalence of meaning and forms between the original texts and the translated version.

Generally, Indonesian students usually have problem in translating from English, as a source language into Indonesian, as a target language. It is well known that the above-mentioned languages 
are from different family language. Many problems have great effect on translation quality. Students who learn English as a foreign language read word by word in their attempt to understand the meaning of text without deciding which words are the most important to help in understanding the whole text (Sakka, Aswad, and Fajriani 2018). Even though after reading and understanding the meaning of the original text, the students sometimes translate it word by word. Consequently, the inability to relate the meaning of a word-by-word translation results in a translation far from its original meaning. It is known that some of English sentence can be translated word by word, but the other cannot. Translating the meaning of idiom also becomes one of students' problems. Since idiom is an important part of daily usage of language.

In the traditional method of teaching, the teachers train students to employ whatever technique that may help them to extract general meaning of the text. Corrective feedback may be is one of technique that can be used in order to optimize the students' improvement on translating. Corrective feedback is effective to facilitate L2 development by providing learners with both positive and negative evidence.

This paper aims to discover the effectiveness of teacher's written feedback on students translating. This research applied the experimental method which the data analyzed quantitatively and qualitatively.

Translation in the action of interpretation of the meaning of a text, and subsequent production of an equivalent text, also called a translation that communicates the same message in another language. The text to be translated is called the "source text", and the language it is to be translated into is called the "target language"; the final product is sometimes called the "target text". (2010,7)

Hatim and Munday define translation as (1) the process of transferring a written text from the source text into the target text, conducted by a translator, or translator in a specific socio-cultural context; (2) the written product, or the target text, which results from that process and which functions in the socio-cultural context of the language; and (3) the cognitive, linguistic, visual and ideological phenomena which are an integral part of (1) and (2). $(2004,16)$

Newmark pointed out translation is rendering the meaning of a text into another language in the way that the author intended the text. The translation was not only translating the language but also the translator should transfer the meaning of the text, so the reader knew about the author intention.

Based on the definitions, it can be said that translation is a process of transferring the first or native language which become the source language into the second language that becomes the target language without changing the idea or meaning of the source language.

Translation as a discipline of knowledge relates to double linkage equivalence (1) the linkage of words or phrases between the source text and the target text. This concept leads to lexical and grammatical elements within both texts, and the articulation of (2) the meaning of the target text that should correspond to the meaning of source text accurately. The concept is on the field of semantics that traces back the conveyance of meaning from the 
source language to the target language for the sake of establishing translation, readability, clarity and accuracy equivalently.

About equivalence, there are two types that very important in translation, they are: (1) lexical equivalents refers to concept in the source text which are known shared in the receptor language, concept in the source language that which are unknown in the receptor language and lexical items in the text which are key terms, translated using a special treatment. If this is the case, lexical equivalences help translator bridges the gap between the source and target texts. (2) Grammatical and Semantic Equivalence. Baker mentioned a grammatical equivalence that affects the diversity of grammatical categories within the source language and the target language with significant changes to come across. For example, the change occurs in grammatical devices such as number, tense and aspects, person and gender. The change also occurs in the grammatical equivalence of voice. The English active voice is translated into the Indonesian passive voice.

The main and major methods of translation are (1) Literal and (2) Free.

\section{Literal translation}

Literal translation involves the conveyance of denotative meaning of words, phrases and sentences in a text from one language to another. Therefore, literal translation works where there is correspondence between two languages in term so semantic and structure.

This method could be applied the three different ways such as word-for-word translation, one-to-one literal translation and literal translation of meaning. The ancient Greek translated texts into Latin used the literal word-for-word approach. A one to one basis of literal substitution was preferred. Here, fluency for target reader is more important than fidelity.

\section{a. Word-for-word Translation}

Word for word translation is the way of transferring meaning of every word of the source language into the target language with its equivalent words. This means to translate individual words. It is a risky method since it may upset meaning. So, it is not recognizing as mature translation practice because it does not takes structural mismatches such as word order and modification differences between languages into consideration.

\section{b. One-to-one Literal Translation}

It is abroad form of translation. In this method, we consider the collocation meaning and translate each SL word or phrase into identical word or phrase in the TL with the same number, grammatical class and type of language. That is a noun is translates into a noun, an adjective to an adjective, and so on. In the same way, an idiom should be translates into an idiom, a collocation into a collocation, a proverb into a proverb, a metaphor into a metaphor, etc. 


\section{c. Literal Translation Meaning}

It is the translation meaning as closely, accurately and completely as possible. This is why sometime it is called close or direct translation. It takes into account the TL grammar and word order. Metaphorical and special uses of language are also accounted for in the TL. This method conveys different meaning in different texts, context and combination with other words.

\section{Free Translation}

Free translation is the act of rendering as closely as possible the wording, structure, and grammar of a source document into the translation. Here, fluency is not as important as fidelity. This is often made for students and scholar who have knowledge of the language they are reading. This method is considered to be better than the previous one, literal translation. Free method means to translate translation that reproduces the general meaning of the original text. It may or may not closely follow the form or organization of the original. It is associated with translating the spirit, or the message, not the letter or the term of the text. It does not translate every single word in a text. The translator can translate the way hr understands. It is convenient both for the translator and the person who read it. As for free translation, it is another translation method whereby an SL literary text is relayed into the TL by reproducing the matter without the manner, or the content without the form. Therefore, it is usually a paraphrase that is much longer than the original and often wordy and pretentious.

But the commonly employed methods of translation could be classified as adaptive translation, semantic translation, idiomatic translation, communicative translation, pragmatic translation, faithful translation, creative translation, etc.

\section{a. Adoptive Translation}

Adoptive translation is a translation method where by the SL text is freely translated in the TL. It is mainly a procedure appropriate to particular circumstances such as translating plays for the stage which aims to achieve particular kind of equivalence that can edited within the TL culture. As a result, the theme, characters, plots are usually preserved, while the SL culture is converted to the TL culture and the text written. There are several literary masterpieces that have been adapted from their SLs into other TLs. This type of translation maybe labeled as "loose free translation" in which some translation are concluded from the SL.

\section{b. Semantic Translation}

Semantic translation must take more account of the aesthetic value of the source language text, compromising on the 'meaning' where appropriate so that no assonance, word-play or repetition jars in the finished version. Further, it may translate less important cultural words by culturally neutral third or functional terms but not by cultural equivalents. It may make other 
small concessions to the readership. It is more flexible admit the creative exception to $100 \%$ fidelity and allow for the translator's intuitive empathy with the original. It is the process of using semantic information to aiding the translation of data in one representation or data model to another representation or data model. Semantic translation takes advantage of semantic that associate meaning with individual data elements in one dictionary to create an equivalent meaning in a second system.

a. Class Equivalence: indicating that class or 'concept' is equivalent. E.g. 'person is the same as 'individual'.

b. Property Equivalence: indicating that two properties are equivalent. e.g. 'Person given name' is the same as "first name'

c. Instance Equivalent: Indicating that two individual instance of objects are equivalent. E.g. 'Dan Dickson is the same person as Daniel Dickson'.

\section{c. Idiomatic Translation}

Idiomatic translation replicates the message of the original but tends to distort nuances of meaning by preferring colloquialisms and idioms where the second exist in the original. Idiomatic translation is a TT oriented method presented by Newmark. There suits of this study showed that this method is a good device for the translator to make their texts more natural as component of the language and also more literary as idioms, proverbs, and etc are the structure which make texts more literary. It was also found that the idiomatic translation can be used where there is a sentence in the ST for which there is a proper equivalence in the TT. The proper equivalent is the one which is as close as the original one semantically and functionally.

\section{d. Creative Translation}

It is not merely substituting words in language $\mathrm{X}$ for words in language $\mathrm{Y}$. It requires a flexible approach that suits the target audience. For example, creative translation includes advertisements with attention-grabbing taglines for products or marketing material. Translation that catches only the literal meaning will not convey the message appropriately and might not even make sense. Creative translation will make the content have the same effectiveness and convey the same impression as the original source text. Capable translators may not be good creative translation. As well as the linguistics skills usually required oaf a translator, creative translation requires the ability to understand and to able to express oneself well, while a sense for language is vital. Here, we can quote an example from the advertisements for hair transplantation.

There are four stages in the translation process that can happen very fast or slow, only once or repeatedly, depending on the intensity of the difficulties encountered by translators. The translation stages are analysis, transfer, restructuring and evaluation. In the 
stages of analysis, translators analyze the text to get the textual or contextual meaning of the text. In the stage of transfer, the meaning or message obtained from the analysis is transferred from the source text to the target text. This stage happens in the translators' mind. In the stage of restructuring, translators write the target text, maintaining the equivalent content, meaning and message of the source text. The stage of evaluation and revision is where the translators evaluate the target text, whether or not it is the same as the source text. If it is not the same, then the target text is revised and the process is repeated from analysis.

Translation is a skill that needs a long process in case to be the good work that can be understood by other readers. The picture below may show the process of translation:

Figure 1. Translation Process

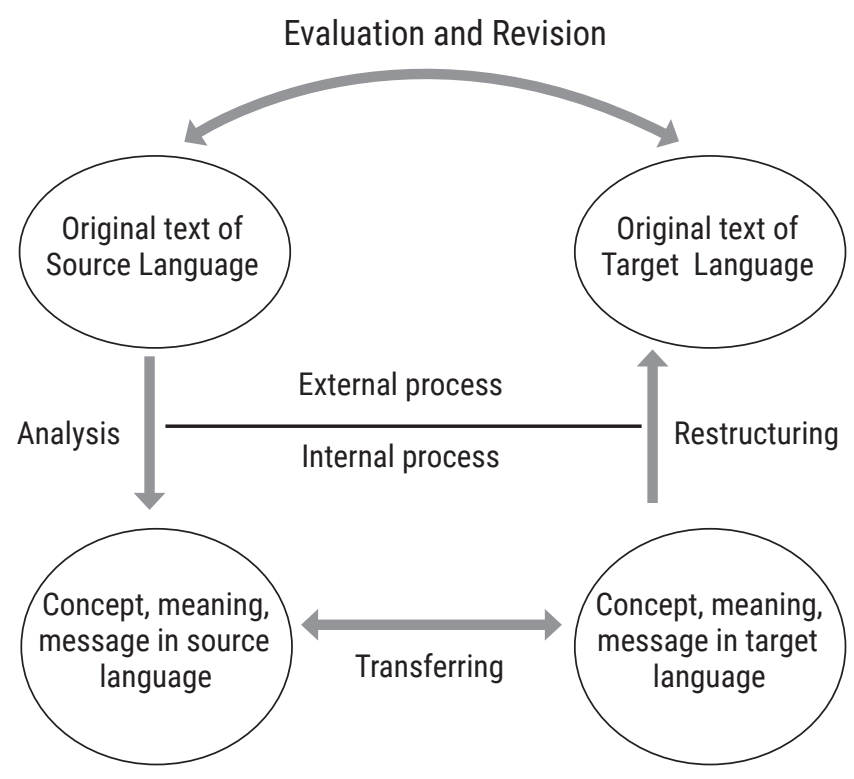

Corrective feedback is defined as a teacher's indication given to students in order to let their written work contain errors (1999). There are many different terms in calling this technique, such as corrective feedback, error correction, and negative evidence (2013). It doesn't matter which term is used since they share the same objective which is to inform students that errors do exist in their written work, and it needs a correction.

The better-known teacher corrective feedback is teacher written feedback. This type of feedback is provided by a teacher by means of writing their comments, correction of errors, etc. on students' pieces of writing. Teacher corrective feedback that involves grammar correction is form-focused feedback (2011)

Types of Written Corrective Feedback (WCF) according to Ellis, there are six type of written corrective feedback. The overview of these types is presented in the following table.

Table 1. Categories of Written Corrective Feedback

\begin{tabular}{|l|l|}
\hline \multicolumn{1}{|c|}{ Type of corrective feedback } & \multicolumn{1}{|c|}{ Description } \\
\hline Direct corrective feedback & $\begin{array}{l}\text { The correction is provided in a place of } \\
\text { incorrect form. }\end{array}$ \\
\hline $\begin{array}{l}\text { Indirect corrective feedback } \\
\text { a) Indicating only } \\
\text { b) Indicating the specific } \\
\text { location }\end{array}$ & $\begin{array}{l}\text { The errors are identified and indicated } \\
\text { without providing the correct form. } \\
\text { a) An error is notified only in the margin or in } \\
\text { a line. } \\
\text { b) An error is underlined. }\end{array}$ \\
\hline $\begin{array}{l}\text { Metalinguistic } \\
\text { a) Brief grammatical description } \\
\text { b) Error codes }\end{array}$ & $\begin{array}{l}\text { Metalinguistic clue of an error is provided. } \\
\text { a) A brief of grammatical explanation of an } \\
\text { error is delivered at the end of text and } \\
\text { numbered. } \\
\text { b) Abbreviation of error codes provided in } \\
\text { the margin. }\end{array}$ \\
\hline $\begin{array}{l}\text { The focus of the feedback } \\
\text { a) Focused b) Unfocused }\end{array}$ & $\begin{array}{l}\text { The correction is provided for all errors or } \\
\text { specified. } \\
\text { a) The correction given only on specific or } \\
\text { targeted features. } \\
\text { b) Many or all error correction is addressed. }\end{array}$ \\
\hline Electronic feedback & $\begin{array}{l}\text { Using a computer to point out the error and } \\
\text { provide the example of correct usage. }\end{array}$ \\
\hline Reformulation & $\begin{array}{l}\text { A native speaker reformulates the writer's } \\
\text { text and maintains the basic content. }\end{array}$ \\
\hline
\end{tabular}

Based on the literature and previous studies, it can be concluded that the corrective feedback may 
help students to improve their writing ability and decrease the error while translating. Many scholars have conducted studies in relation to the corrective feedback and translation. Some of them are:

Sermsook, et.al (2017) founds teacher corrective feedback would be help for EFL students' writing improvement. The research focuses on feedback provided to correct the grammatical errors. In that research, they found that this type of errors can obstruct the effectiveness of students' writing.

Lin Jiang and Hailing Xiao (2014) indicated that, pedagogically, the current findings indicate that the provision of written CF in reviewing learners' texts is necessary and effective, and teachers should not hesitate to provide written CF in English (writing) teaching so as to draw learners' attention to the gaps between the language and the target language, which may promote language acquisition.

Al-Musawi (2014) found that translation may be used as learning strategy. The study found that the student use translation to learn English Vocabulary, to read, to write, and check comprehension.

\section{FINDING AND DISCUSSION} Finding

Figure 2. Students' Wrong Translated STUDENTS' WRONG TRANSLATED

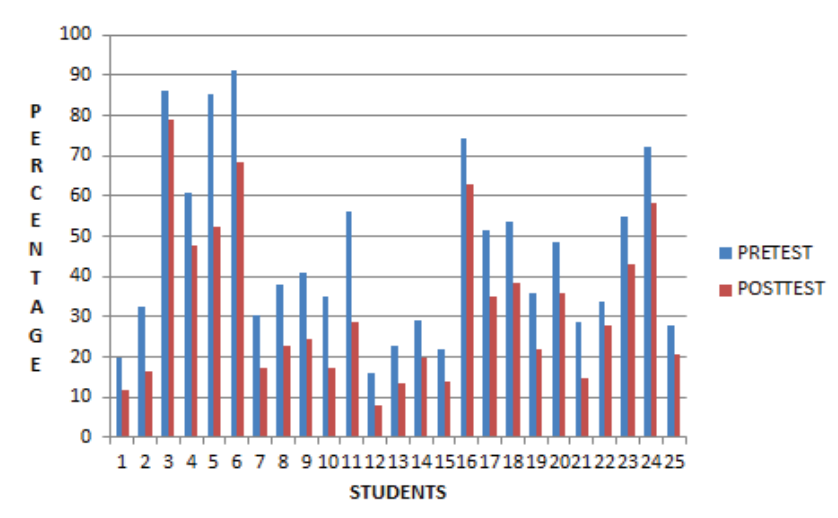

The data above is about number of incorrect words translated by students in percentage. There are various numbers of words performed by students. In pretest, the number of words with the most errors is 130 words, while the number of words that are least wrong is 24 words. Besides that the data also shows the percentage of the number of incorrect words from all the words in the reading.

While in posttest, the number of words with the most errors is 119 words, while the number of words that are least wrong is 12 words. Besides that the data also shows the percentage of the number of incorrect words from all the words in the reading.

The data revealed that the suitability of students' translating was reduced after being given reinforcement which is corrective feedback. By using corrective feedback, the teacher is able to detect some common mistakes done by students. This study is highlight on the effect of teacher' written corrective towards students' translation improvement which focused on word, phrasal verb and sentence.

The study found that the students minimally done some mistakes while translating. The lexical problems may categorized into some parts: 1) translating words by words, 2) translating phrasal verb word by word, 3) meaning of language target is not appropriate with source language, 4) missing some words makes the incomplete meaning sentence.

In lexical problems, both source language and target language have word which is having directly equivalent in both languages. They only have one meaning and can be translated word for word because the word has same meaning both in source language and target language 
Translation typically has been used to transfer written or spoken SL texts to equivalent written or spoken TL texts. In general, the purpose of translation is to reproduce various kinds of texts-including religious, literary, scientific, and philosophical textsin another language and thus making them available to wider readers.

If language were just a classification for a set of general or universal concepts, it would be easy to translate from an SL to a TL; furthermore, under the circumstances the process of learning an L2 would be much easier than it actually is.

Translating process may have some troubles for the translators both in spoken and written. The differences between source language (SL) and target language (TL) and the variation of the other language culture make the translating process in a real challenge.

Besides lexical problem, the students also get problem in translating phrasal verb. The students maybe, in the school, do not learn the phrasal verb. So, the students interpret the phrasal verb lexically.

To cover up the students' problem in translating, the teacher implements the strategy namely written corrective feedback which can help the students to improve their translation skill. The better-known teacher corrective feedback is teacher written feedback. This type of feedback is provided by a teacher by means of writing their comments, correction of errors, etc on students' translation task.

To improve the students' translation, the teacher gives feedback after the treatment done in every meeting. The teacher gives correction on the errors that made by the students. The teacher focuses on the students' translation on lexical problems which are word for word and phrasal verb translating.

As the result, the students get more improve when translating which can be seen on the posttest result. Teacher analysis the students' result in translation as the students' media to improve their language proficiency in learning second language. The teacher written corrective feedback may be a strategy to learning second language. Bagheri and Fazel found that translation studies assist students in acquiring writing, facilitates their comprehension, helps them develop and express ideas in another language, and increases their motivation to learn English. The research also found that interaction between the students and the teacher while doing the translation makes them easy to learn about the target language. Through collaboration, the students are able to learn the new language easier and faster. In this sense, the use of translation is considered as a social strategy where students are in direct contact with the teacher and other in language classes.

To sum up, the students generally make lexical problems in translating the task. The Teacher written corrective feedback helps students to learn the target language easier by helping the students in correcting their error mistakes in translation.

\section{CONCLUSION}

The differences between the two languages due to their belonging to two different language families cause the main problems for the students or translators. The students face two main problems in their translation namely lexical problems and phrasal verb translating. 
To improve the student's translation, the teacher written corrective feedback are helpful to get the students easier to learn the target language in order to increase their English proficiency skill. This type of feedback also can lead the students to understand their mistake in their translation.

\section{REFERENCES}

A. Abu Seileek and A. AbuAlsha'r. (2014) Using peer computer-mediated corrective feedback to support EFL learners' writing. Language Learning \& Technology, vol. 18 (1), pp. 76- 95.

Al-Essawi, S.F. (2010) Translated book about "The Annual Administrative Report”.AResearch for Fulfillments the requirements for Diploma of HADAF Center.

Baker, M. (1992) In the Other Word: "A Course Book on Translation" London: Routledge. DOI: 10.1515/cllt Journal of Second Writing.

Bitchener, J., Young, S., \& Cameron, D. (2005). The effect of Different Types of Corrective feedback on ESL Students' Writing.Journal of Second Language Writing, 14.

Cepni, S. B. (2016). A Replication Study: Oral Corrective Feedback Types; Two Approaches Compared. Procedia Social and behavioral Sciences, 323, 520528.

C. V. Beuningen. (2010). Corrective -2013-0018, June 2013.

Bitchener, J. (2008). Evidence in Support Of Written Corrective Feedback.

feedback in L2 writing: theoretical perspectives, empirical insights, and future directions. International Journal of English Studies, vol. 10 (2), p. 1- 27.

Ellis. R. (2007). A Typology of Written Corrective Feedback Types. ELT Journal, Vol. 62 (2), p. 97-107.

Farrokhi, F., \&Sattarpour, S. (2012). The Effect of Direct Written Feedback on Improvement of Grammatical Accuracy of High-Proficient L2 Learner. World Journal of Education, 2(2) p.49-57.
K. Rustipa. (2015). The Benefit of Indirect Comprehensive Error Corrections in Improving Advanced EFL Learners' Writing Accuracy. Proceedings: The 2nd International Languageand Language Teaching Conference, p. 551-557.

Kaplan, R.S., \& David, N. (1996).The Balanced Score Card: Translating Strategy into Action. Harvard Business School Press.

Karim, K., \&Nassaji, H. (2013). The Role of Corrective Feedback in Second Language Writing.

Khalifa, Elsadig Mohamed. (2015). Problems in Translating English and Arabic Languages' Structure: A Case Study of EFL Saudi Students in ShaqraUniversity. European Journal of English Language and Literature Studies, Vol.3, No.4.

Kim, K., \&Clariana, R. B. (2015).Knowledge Structure Measure of Reader's Situation Models Across Languages: Translation Engenders Richer Structure. Technology, Knowledge and Learning, 20, 249-268.

Larson, L. M. (1984). Meaning Based translation, A guide TO Cross Language, Equivalence. Lanham: University Press of America.

Lightbown, P.M \& Spada, N. (1999). How Language Are Learned. Oxford, UK: Oxford University Press.

Meyer, B.J.F., \& Poon, L.W. (2001). Effects of Structure Strategy Training and Signaling on Recall of text. Journal of Educational Psychology, 93 (1), p.141159.

Newmark, P. (1988). A Text Book of Translation. Prentice Hall, New York.

Nida, E. and C.R Taber. (1991). The Theory and practice of Translation, Vol.2, No.1. P.20

Nolan, J. (2005). "Behind Inverted Commas" Translation and Anglo-German Cultural Relations in the Interpretation: Technique and Exercises.

Razali, R., \& Jupri, R. (2014). Exploring Teacher written feedback and students revisions on ESL Students' Writing. IOSR Journal of Humanities and Social Sciences, 19 (5), p.63-70.https://doi. org.10.9790/0837-19556370 
Sakka, Wahyuni, Muhammad Aswad, and Fajriani Fajriani. 2018. "Enhancement of English Student Learning Results through Total Physical Response (TPR) Method." EDUVELOP (Journal of English Education and Development) 1 (2): 86-95. https:// doi.org/10.31605/eduvelop.v1i2.31.

S. Loewen. (2012). The role offeedback. In A. Mackey \& S. Gass (Eds.). The Routledge Handbook of Second Language Acquisition, Malden, MA: Wiley-Blackwell, p. 24-40.

Srichanyachon, N. (2012). Teacher Written Feedback for L2 Learner's Writing Improvement.
Silpakorn University Journal of Social Sciences, Humanities and Arts, 12 (1), p.7-17

Y. Sheen. (2007). The Effect of Focused Written Corrective Feedback and Language Aptitude on ESL Learners' Acquisition of Articles. Tesol Quarterly, vol. 41 (2), p. 255-283.

Yingjun, L. (2014). Status and Prospect of Machine translation and Translation Technology Research. Chinese Science \& Technology Translators Journal, 01,24-27. 